instrument possesses and which the ear perceives as a vowel. Different vowels are produced by modulating the resonance of the cavities in much the same way as when reinforcing a vocal cord note. However, the vowel resonances ('formants') need not bear harmonic relation to each other. It follows that, in singing, the cavities are required to produce resonances which must be harmonics of the vocal note and at the same time fall within the formants of the vowel. These two requirements may conflict, and the claims of the note must then take precedence. This is the case in the upper range of the soprano voice where vowel production becomes a matter of great difficulty. The lower voices, being richer in harmonics within the resonant compass, are less troubled by this effect.

Much research has been carried out to determine the range of resonance in the throat and mouth cavities employed in the various voices, and recently this work has been greatly facilitated by the introduction of new electro-acoustic techniques. The normal range of resonance of the throat cavity for the male voice extends from $A_{1} b$ to $E_{2} b$ in the treble clef. Bass and baritone notes from the lowest up to $E_{1}$ b (on the bottom line of the treble clef) are reinforced on whatever harmonics lie within this compass. Notes lying between $E_{1} b$ and $G_{1}$ are resonated on the fundamental by a forced enlargement of the throat cavity. In women the normal compass of resonance stands squarely in the middle of the soprano voice extending upwards from the $G_{1}$ in the treble clef to the $F_{2} \#$ above. The notes within this range will naturally be reinforced on the fundamental, while lower tones find resonance on the first or second harmonic. When the voice rises above $F_{2} \#$ the throat resonance must be raised above its normal range, and this is achieved in trained voices by an enlargement of the throat cavity aperture.

Mr. Mackworth-Young has himself demonstrated the existence of two resonant zones in the throat having a compass of four semi-tones each in the men's voices (four and eight semi-tones in women's voices). It was found that if the vocal note happened to have harmonics in both zones, then both harmonics were heard. Notes which have two harmonics within the same zone may be resonated on either one but not both. The exact significance of this discovery awaits interpretation.

The normal compass of resonance for each voice shows a remarkable uniformity among singers of differing ages and nationality, individual variations rarely amounting to more than a semi-tone in either direction. The vowel, demanding as it does absolute pitch of resonance, is even more exacting in its requirements. This uniformity is achieved because the note of a Helmholtz resonator varies according to its size in relation to its opening; and as the mouth and throat capacities of the two sexes and various ages differ, so the mouth openings differ with them, thus maintaining the same proportions.

The throat cavity resonance on any particular note appears to be independent of the vowel which is being sung. It would appear, therefore, that throat resonance plays little or no part in vowel production, but the matter is still open to question. The nature of the vowel sounds has been under investigation since the beginning of the nineteenth century, and the pitches of the formants involved in the production of each vowel are now well established. For some vowels the lower formant does lie within the compass of throat resonance, while the upper formant is undoubtedly supplied by mouth resonance. For other vowels (for example, ai and ee) the mouth is divided by the tongue into two cavities which appear to provide the two formants independently of the throat resonance.

Much remains to be done to elucidate the acoustical processes in full of orchestral wind instruments; so it is with the voice. A good singer may be readily distinguishable from an indifferent on $\theta$ merely by listening to him; but if the indifferent singer is to be helped to improve, the scientific principles underlying the good singer's skill must. be studied. In particular, studies should be made. of 'attack' and 'vibrato' as practised by trained singers.

\section{THE INTERNATIONAL BOTANICAL CONGRESS IN PARIS}

IN 1854 the Société Botanique de France was 1 founded, and it was very fitting that the centenary of this event should coincide with the meeting of the Eighth International Botanical Congress in Paris during July 2-14. The Congress was very well attended; the incomplete list of members and those accompanying members contains more than two thousand names, derived from about seventy different countries. Thus this Congress was even more truly international than that held in Stockholm in 1950.

The work of the Congress was divided between twenty-seven sections : International Union of Botanical Sciences; Nomenclature; Terminology; Taxonomy; Palæobotany; Palynology ; Phytogeography; Morphology and Anatomy; Cytology; Genetics; Plant Physiology ; Agronomy ; Forestry; Standardization of Raw Materials of Plant Origin; Ethnobotany; Bryology ; Phycology ; Lichenology; Mycology ; Plant Pathology ; Bacteriology ; Protection of Materials and Equipment; Soil and Water Mierobiology ; Nature Conservation; History of Botany; Botanic Gardens; Mediterranean Botany.

The above list may seem to disperse the subject over a very wide field, but it should also be noted that many sections were still further divided; for example, there were three sub-sections of Physiology, namely, Nutrition, Growth, Physiological Ecology. On a day chosen at random there were thirty-five different papers being read simultaneously; thus the subject had been so dissected that there were very few papers of general interest, and those attending the Congress had to be very ruthless in their decisions which section to attend, otherwise much valuable time was lost trying to keep track of two fields of interest housed in widely separate parts of the Sorbonne. One wonders if this process of sub-division has gone too far and there really is no longer a science called 'botany' but only some twenty or thirty separate sciences. One factor, however, eased this situation. The nine volumes comprising the Congress papers were available at the beginning and enabled one to decide which communications were most appropriate to one's own interest.

Most sections, while allowing time for miscellaneous communications, concentrated on a few main topics on which colloquia were held. These colloquia took the form of a rapport which usually summarized the position and lasted for an hour, followed by 
discussion for thirty minutes. Then came a series of brief communications by workers in the field under discussion. Thus one was given a fairly comprehensive background plus an indication of the growing points of the topic, and the discussion of the points raised was also very valuable. There were also many joint colloquia; for example, a discussion of "Quaternary Climate" organized by the Palynology Section was attended by the Phytogeography Section, while one on "Fungal Growth" embraced mycologists and physiologists.

The programme on the whole was well organized, although a lax attitude to time-keeping often meant that valuable communications were crowded out or had to be presented in a form so abbreviated as to be incomprehensible and almost valueless. There was also a certain confusion in some sections where papers were allocated 'time-units'. At an international congress, the symposium is the best form of meeting ; but the clarity of the paper should not be sacrificed to length.

There was much variety between the sections in the use of language. The Congress programme laid it down that French and English were the preferred languages, but the writer also heard papers in German. One agrees that German should be allowed at such meetings; but in the discussions the use of an interpreter was urgently needed on several occasions, a question being asked in one language, answered in another, while part of the audience was more at home in a third. Translation, of course, uses valuable time but it is worth it, for those who do not understand may be those who might contribute most to the discussion.

It is impossible to give an adequate idea of the topies dealt with during the Congress, but there should be some indication of the subjects studied. Among others, the following were very valuable and interesting symposia : secondary and tertiary floras (palæobotany); ecology of cold areas (phytogeography and ecology); experimental embryology (morphology); extra-nuclear inheritance (genetics); photosynthesis (physiology); photoperiodicity (physiology); morphological and physiological gradients (morphology and anatomy); forest pathology (forestry); ecology of marine alga $\theta$ (phycology); bryogeography (bryology) ; taxonomy of lichens (lichenology); fungal pigments (mycology); virus diseases (plant pathology); etc.

The social side of the Congress was well organized. The opening plenary meeting was held on July 2 in the Grand Amphitheatre of the Sorbonne under the presidency of the Rector of the University of Paris. Short addresses were given by Profs. Schopfer (Berne), Thimann (Harvard-Cambridge) and Heim (Paris). On the evening of Saturday, July 3, the Muséum National d'Histoire Naturelle gave a reception to all members of the Congress in the Zoo at Vincennes. Sunday was free to take advantage of the facilities offered by the Congress to visit the gardens and greenhouses of the Museum and the Arboretum Vilmorinianum in Verrières-le-Buisson. On Wednesday, July 7, at 5 p.m., the Congress met with the Société Botanique de France, and official delegates presented addresses and good wishes on behalf of their parent societies. M. Roger de Vilmorin delivered a short address and showed many beautiful coloured slides of the vegetation of France.

On Tuesday there was a general excursion to Versailles. The final general excursion was held on July 9 , when many members enjoyed a day trip to
Fontainebleu. The many members who attended had a relatively fine day which made botanizing in the Forest a pleasure.

There were sundry receptions for official delegates by various bodies; but the Congress concluded its official business at a plenary session on Monday, July 13. Here addresses of thanks and good wishes were delivered and the Congress closed with the decision that the Ninth International Botanical Congress should be held in Canada in 1958.

There were many excursions, some fairly local, some going as far afield as North Africa. In addition, the Section Mediterranean Botany held an extension of the Congress in Nice, where in addition to communications there were many excursions along the coast and into the mountainous hinterland.

In such a brief account of the proceedings of the Congress it is inevitable that emphasis is laid on those aspects of the proceedings which deserve re-examination. But criticism of details should not in any way detract from the general excellence of the work of the organizing committee. The Congress viewed in toto ran smoothly and well, and it is to be hoped that subsequent Congresses will follow the admirable precedents set by those at Stockholm and Paris.

A. R. Gemmell

\section{LOCALIZATION IN THE CEREBRAL CORTEX}

A SYMPOSIUM on localization of function in the cerebral cortex was held in Oxford on September 8. Arranged by Section I (Physiology) of the British Association jointly with the Physiological Society, this symposium brought together workers from a number of disciplines converging on neurology and a large audience evidently drawn from many sections of the Association. Although the problem of cerebral localization is nowadays too complex to provide a clear-cut issue, there can be no doubt that it represents a convenient theme around which to group a variety of contemporary inquiries in the neurological field. The organizers of the symposium are to be congratulated on their choice of a topic which is not only of central importance in neurology but which also can be relied upon to attract widespread interest among biologists.

\section{Intelligence and Brain-Size}

The symposium was introduced-most appropriately-by Dr. E. D. Adrian, president this year of the British Association, who raised two important, if closely related, issues. First, the question of brain size in relation to the type of activity commonly called intelligent; and secondly, the mode of specialization of function within the cortex. As regards the first issue, Dr. Adrian pointed out that absolute size of brain no less than its general arrangement would appear an important factor in the evolution of the mammalian nervous system. He suggested that this might be explained either by supposing that an increase in brain-size permits greater subdivision-and hence localization-of function, or by assuming that intelligent activity depends upon a large amount of unspecialized cortical tissue. Both answers, in Dr. Adrian's view, are right up to a point, and the real question we have to ask is how much of the brain is allotted to special activities and "what happens to the rest". 